\title{
Excel in CBCT with BDA masterclass
}

The British Dental Association's (BDA's) next 'CBCT small volume reporting masterclass' is taking place on Saturday 13 June and Saturday 18 July 2020, at the $\mathrm{BDA}$, London. The masterclass is a unique, hands-on course, designed for clinicians who wish to excel and become competent in the justification, optimisation and reporting of small field of view cone beam computed tomography (CBCT).

The masterclass is delivered in a combined learning format to suit all learning styles and fit around busy clinical practice, and led by Simon Harvey, Consultant in Dental and Maxillofacial Radiology, Honorary Lecturer, King's College London Dental Institute and Shanon Patel, Consultant Endodontist and Senior Lecturer in Endodontics, King's College London Dental Institute and Specialist Practice.

Drs Harvey and Patel's article Guidelines and template for reporting on CBCT scans was published in the previous issue of the $B D J .{ }^{1}$

For further information, please visit bda. org/cbct.

\section{Speaker Q\&A}

\section{What made you devise this course?} Simon: As the use of CBCT increased dramatically in the last few years, many colleagues asked about CBCT training in order to get the most out of this exciting technology. I have always been aware of the perceived divide between clinicians and non-clinicians (radiologists), and many CBCT courses lack clinician context. We wanted to design a course that was taught with a radiologist, but with a larger input from clinicians who use CBCT - so it makes the skills learnt transferable to clinical practice.

Shanon: Over the years we have been asked by so many of our past and previous postgraduates, as well as dentists attending lectures, if I would run a CBCT course. Simon and I looked at the current CBCT courses and realised that there was a lack of a comprehensive, all-encompassing CBCT course which was led and taught by experienced clinicians who were not only early advocates of CBCT, but also well know educators.

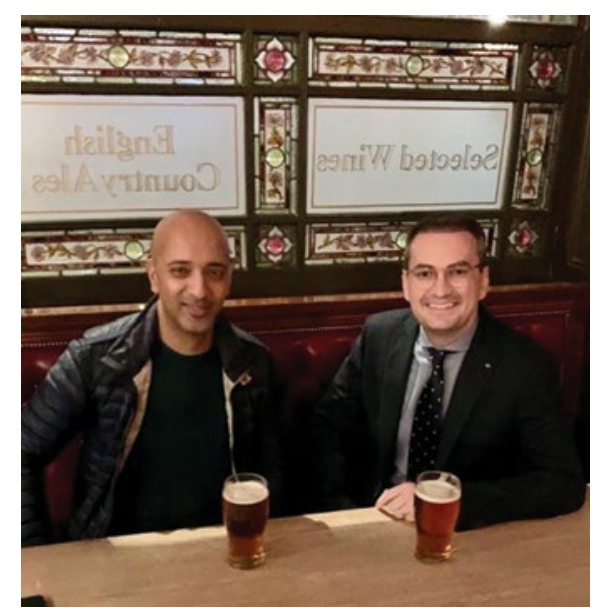

Simon (Consultant Dental and Maxillofacial Radiologist) (right) and Shanon (Consultant Endodontist) first met and struck up a fantastic working relationship at King's College London Dental Institute

\section{What makes the BDA CBCT masterclass novel?}

From the outset, we wanted this course to be the 'go to' CBCT course for clinicians who wanted to be competent in requesting and reporting on their CBCT scans.

The small class sizes ( $<20$ delegates) means that sessions are interactive and informal - we all learn from each other!

The course is based on the European Academy of DentoMaxilloFacial Radiology CBCT training guidelines for level 2 - reporting. We have created a blended learning format, with a mix of contact days and reporting exercises to complete at home. This means the course can fit around your life and practice. We ask delegates to recap the physics regarding CBCT before the first contact day with the supplied textbook (written by Shanon and Simon). It means we can jump straight to practical CBCT reporting on the first contact day.

Day 1 consists of a series of clinically relevant presentations on CBCT, starting with software manipulation and dentoalveolar anatomy. Then we progress to CBCT in relation to endodontics, dental implant planning, oral surgery and orthodontics. Each presentation is interactive and delegates are provided with high-resolution laptops.

Reporting assignments are given to delegates to cover in their own time; they are then encouraged to present one of the cases to the group on day 2 . The faculty mark the assignments and personal feedback is also given thus helping delegates to reinforce what they have learnt. Day 2 also has a presentation on CBCT problem solving and advanced imaging in relation to dental implants.

\section{Tell us a little about you?}

Shanon: I am a consultant endodontist, I work part-time in a multi-disciplinary specialist practice in Central London and at King's College London Dental Institute where I teach in the Postgraduate Endodontics unit. I lead a research group carrying out a lot of clinical research validating the use of CBCT in Endodontics. I have also been the lead author of the European Society of Endodontology's position statement of the use of CBCT in endodontics (2014, 2019).

Simon: I am a consultant at the Eastman Dental Hospital in London. My subspecialty interests are salivary gland interventional radiology (baskets, balloons etc) and CBCT; I limit my practice to these areas. I also studied law after my dental degree and sit on the advisory committee for one of the dental indemnity companies. I really enjoy education and have been teaching undergraduates and postgraduates for a decade.

We are privileged to also have Dr Louise Ormondroyd (Consultant Oral Surgeon) who divides her time between working in the Oral Surgery unit at Guy's Hospital managing patients with complex oral surgery problems, as well as teaching undergraduates and postgraduates. Dr A. J. Ray-Chaudhuri is a Consultant in Restorative Dentistry at the Royal Sussex in Brighton and treats patients with complex hypodontia with implants and prosthodontics. Dr Andrew Dawood is a very experienced implant surgeon, early advocate of CBCT and director of Cavendish Imaging.

The entire teaching team are experienced clinicians as well as well-respected educators in their respective specialties. They have all been using CBCT in their daily practice for $10+$ years.

\section{References}

1. Harvey $S$, Patel $S$. Guidelines for reporting on $C B C T$ scans. Br Dent J 2020; 228: 15-18. Available at: https://www.nature.com/articles/s41415-019-1115-8 (accessed January 2020). 